\title{
Supply-Side Subsidies to Improve Food Access and Dietary Outcomes: Evidence from the New Markets Tax Credit
}

\author{
Matthew Freedman and Annemarie Kuhns*
}

October 2017

\begin{abstract}
In an effort to improve diet and health outcomes, policymakers have increasingly turned to supply-side subsidies aimed at encouraging investment by supermarkets and other food retailers in low-income areas. This paper examines whether the U.S. federal government's New Markets Tax Credit (NMTC) has affected the entry of retail food establishments, and in turn food shopping and purchasing patterns, in low-income communities. To identify the impacts of the program, we take advantage of a discontinuity in NMTC funding generated by the formula used to determine the eligibility of census tracts for investment under the program. We find that the NMTC Program has had modest, but positive impacts on supermarket entry in low-income communities. Based on household-level scanner data, there are no detectable effects on households' food purchasing patterns in affected neighborhoods, at least in the short run.
\end{abstract}

JEL Codes: H25, I18, R23

Keywords: Place-based policies; retail food; tax incentives; community health; regression discontinuity

\footnotetext{
${ }^{*}$ Freedman: University of California-Irvine, Department of Economics, 3151 Social Science Plaza, Irvine, California, 92697 (e-mail: matthew.freedman@uci.edu). Kuhns: U.S. Department of Agriculture, Economic Research Service, 355 E Street SW, Washington, DC 20024 (e-mail: amkuhns@ers.usda.gov). We would like to thank Jan Brueckner, Jessie Handbury, Matthew Harding, Mike Kruger, Brian Stacy, Rusty Tchernis, and Matthew Weinberg as well as numerous seminar participants for helpful comments. Freedman would also like to thank the USDA's Economic Research Service for generous financial support. Any opinions, findings, recommendations, or conclusions are those of the authors and do not necessarily reflect the views of the Economic Research Service, U.S. Department of Agriculture. The analysis, findings, and conclusions expressed in this paper also should not be attributed to Information Resources, Inc. (IRI) or the Nielsen Company.
} 


\section{Introduction}

In an effort to improve access to nutritious and affordable food, policymakers around the world have increasingly turned to supply-side subsidies aimed at encouraging investment by supermarkets and other food retailers in low-income areas. For example, several cities and states in the U.S. have attempted to address perceived food access problems by providing property tax abatements or other tax incentives to retail food establishments that locate in certain neighborhoods.

Evaluating the effects of these initiatives is difficult for two reasons. First, programs that aim to subsidize the entry of healthy food retailers tend to be limited in scale. Second, finding suitable comparison groups is challenging given that communities eligible for subsidies are typically not randomly selected; as a result, it is often unclear whether observed changes in areas that receive subsidized investment are attributable to the investment itself or to other, possibly unobserved neighborhood characteristics.

Large-scale place-based policies that subsidize commercial investment provide an opportunity to study the impacts of potentially many store openings over a broad geographic area. To the extent that they induce the entry of supermarkets and other food retailers in low-income neighborhoods that would not have otherwise occurred, they can also make firm entry exogenous with respect to consumer preferences and help to isolate the role of healthy food access in giving rise to observed differences in food purchasing patterns across communities. To explore the potential for supplyside subsidies to improve food access and change food purchasing patterns, this paper examines the effects of the U.S. federal government's New Markets Tax Credit (NMTC) Program, a national program that offers tax incentives to encourage private investment in low-income neighborhoods. To identify the effects of the program, we exploit a discontinuity in NMTC funding generated by the formula used to determine census tract eligibility. The discontinuity creates quasi-experimental variation in subsidized investment around a certain income threshold; tracts with median incomes below the threshold are eligible to receive NMTC-subsidized investment, while tracts with median incomes above generally are not eligible.

We first examine the NMTC's impacts on the entry of retail food establishments in low-income areas across the country during the 2000s. Combining information on NMTC-subsidized investments from the U.S. Treasury with comprehensive data on retail food establishments from A.C. Nielsen's TDLinx, we compare outcomes among tracts within a narrow window around the 
income threshold determining eligibility under the program. While it limits the generalizability of the results beyond the subset of tracts close to the threshold, this approach allows for causal inferences regarding the impacts of the NMTC on retail food investment. We find that the program induces modest, but positive growth in the local retail food industry, with the effects concentrated among supermarkets.

We then take advantage of household scanner data from Information Resources, Inc. (IRI) to explore the NMTC's impacts on food shopping and purchasing patterns among households in lowincome neighborhoods. We find that, while the arrival of new supermarkets may have led some households to redirect purchases, it had no discernable effects on the healthfulness of consumers' food purchases, at least over the short time horizon we consider.

\section{Background}

There exist large disparities in nutrition and diet-related health outcomes across different socioeconomic groups in the U.S. Preferences for less healthy foods, higher prices for healthy foods, and limited access to healthy foods could each contribute to these disparities. The latter has received particular attention among policymakers, who in recent years have advanced legislation that seeks to increase access to healthier foods in poor communities (CDC 2011, Aussenberg 2014).

It is not immediately clear, however, that increasing access to healthy food in lower income areas will reduce nutritional and health disparities (Wrigley 2002, Bitler and Haider 2011, Taylor and Villas-Boas 2016). Differences in consumption patterns could be driven as much, if not more, by differences in preferences and/or price sensitivities. Indeed, in a comprehensive study of food purchases made between and within stores by higher and lower income households, Handbury et al. (2016) find that differences in access play only a minor role in explaining observed differences in food expenditure patterns.

While some recent case studies on the food consumption and health effects of single store openings in low-income areas corroborate these findings (Cummins et al. 2014, Elbel et al. 2015), others document positive effects of improved access on healthy food expenditures among households in distressed communities (Wrigley et al. 2003, Weatherspoon et al. 2013). In such case studies, however, one might be concerned about both the generalizability of the results as well as the non-random selection of neighborhoods by supermarkets. Our study takes a different 
approach than past research not only by using data on retail food store openings across the U.S., but also by taking advantage of quasi-experimental variation in the location of this investment generated by particular features of the NMTC Program.

\section{The New Markets Tax Credit Program}

The NMTC Program was established under the Community Renewal Tax Relief Act of 2000 and is overseen by the U.S. Department of Treasury. The program is intended to promote greater investment into operating businesses and real estate projects located in low-income neighborhoods across the country. It does so by providing investors a tax credit against their federal income tax in return for making equity investments in certain, Treasury-approved financial institutions known as Community Development Entities (CDEs).

Tax credit allocations to CDEs, which totaled \$26 billion between 2003 and 2009, are awarded competitively by the Treasury's Community Development Financial Institutions (CDFI) Fund. After being awarded an allocation, a CDE has five years to use the proceeds to make qualified low-income community investments (QLICIs) of equity or debt capital. Historically, the majority of QLICIs have taken the form of loans to developers and businesses, which can be offered at below-market interest rates and with other preferential terms because investors' returns are partly covered by the tax credit. While CDEs have significant latitude in determining what types of investments to make, about two-thirds of CDE investment has gone to commercial real estate development. Much of the remaining third are loans to businesses. ${ }^{1}$ In the early years of the program, the median size of NMTC projects was $\$ 3.7$ million, and program funds covered over one-third of project costs on average (U.S. GAO 2010, Abravanel et al. 2013).

CDEs must invest "substantially all" of the equity they receive in certain areas called "lowincome communities" (LICs). During the 2000s, neighborhoods could qualify as LICs in several ways. First, census tracts with median family income (MFI) that does not exceed $80 \%$ of the greater of their metropolitan statistical area's (MSA's) MFI and their state's MFI qualify. ${ }^{2}$ Any tract with

\footnotetext{
${ }^{1}$ A very small fraction of NMTC funds help to finance residential real estate development, in part because the financing of rental property development is generally not allowed under the program.

${ }^{2}$ For tracts outside MSAs, only the statewide MFI is relevant in determining the income ratio.
} 
a poverty rate of at least $20 \%$ also qualifies. A small number of "low-population" and "rural, high out-migration" tracts also qualify. ${ }^{3}$

During the 2000s, $39 \%$ of the 65,443 tracts in the U.S. qualified as LICs. Nearly all LICs (98\%) qualified either on the MFI ratio criterion or on the poverty rate criterion. Of those that qualified on one of these two criteria, $95 \%$ qualified on the MFI ratio criterion. The result is a discrete dropoff in tract eligibility at the $80 \%$ MFI ratio cutoff; the percentage of tracts designated as LICs falls from $100 \%$ among tracts below the cutoff to $11 \%$ among tracts with MFI ratios between 0.8 and 0.9. This nonlinearity in eligibility generates quasi-exogenous variation in the location of NMTCsubsidized investment, variation that we can use to identify the causal effects of that investment on local retail food markets.

Prior work on the NMTC has found mixed impacts on communities. Freedman $(2012,2015)$ examines the effects of NMTC investment on aggregate employment and housing conditions within targeted neighborhoods and finds modest positive impacts. Harger and Ross (2016) study whether the NMTC affected the entry and expansion of establishments across different broad industries and find that it had a disproportionate effect on manufacturing and retail. However, Harger and Ross do not examine its impacts on retail food specifically, nor do they consider other community-level impacts of the subsidized investment beyond its effects on establishment entry and employment growth.

Improving access to healthy foods in underserved communities was not initially a goal of the NMTC Program. However, investment in food production and distribution businesses are eligible uses of NMTC funds as long as the assets of the businesses are located in LICs. A sizable fraction of QLICIs during the 2000s were in retail food, which is attributable to several features of the industry. ${ }^{4}$ First, grocers are unlikely to violate program rules on excessive working capital. Second, most business activities that are not eligible for NMTC financing (e.g., gambling, tanning salons, and liquor) are either seldom combined with food retailing or represent a sufficiently small share of revenues as to not disqualify them for financing. Third, supermarkets do not change ownership

\footnotetext{
3 "Low-population" tracts have populations less than 2,000, are located in federal Empowerment Zones, and are contiguous with another LIC. "Rural, high out-migration" tracts are located outside MSAs, have MFI not exceeding $85 \%$ of statewide MFI, and have net out-migration between 1980 and 2000 of at least $10 \%$.

${ }^{4}$ Determining the exact fraction is difficult given that some CDEs provide no or only vague descriptions of their investments. Based on business descriptions provided, over 6\% of QLICIs are explicitly in retail food. This is a lower bound, however, since some of investments in commercial real estate could include retail food. Of those projects reporting tenant businesses in telephone surveys, $14 \%$ reported grocery stores, making it the second most common type of tenant business (Abravanel et al. 2013).
} 
frequently, which means that the seven-year NMTC period is less problematic than for businesses in other sectors (Reinvestment Fund 2011).

Anecdotal evidence from CDEs suggests that the NMTC has helped to overcome certain barriers to retail food investment in low-income neighborhoods, which include poor infrastructure, zoning issues, traffic patterns, parking, and a lack of large parcels of land (Food Marketing Institute 1998, Short et al. 2007, Ver Ploeg et al. 2009). In 2010, the Obama administration's Healthy Food Financing Initiative lauded the NMTC's "proven track record in expanding access to nutritious foods by catalyzing private sector investment."

\section{Empirical Strategy}

In this section, we outline our strategy for identifying the causal effects of supply-side subsidies on food access, and in turn the effects of quasi-exogenous changes in food access on food shopping and purchasing patterns. The basic regression of interest is

$$
\Delta y_{i}=\beta_{0}+\beta_{1} N M T C_{i}+\mathbf{X}_{i} \mathbf{\Omega}+\varepsilon_{i}
$$

where $\Delta y_{i}$ is the change in outcome $y$ for tract $i, N M T C_{i}$ is the amount of NMTC-subsidized investment in tract $i$, and $\mathbf{X}_{i}$ is a vector of initial tract characteristics. The main parameter of interest is $\beta_{1}$, relating the amount of NMTC investment to changes in outcomes of interest. However, using OLS to estimate this regression is likely to yield a biased estimate of $\beta_{1}$, as unobserved features of neighborhoods may influence the likelihood of receiving NMTC investment and independently affect outcomes.

To address this endogeneity issue, we follow Freedman (2012) and exploit a regression discontinuity (RD) design. Specifically, we focus on a select group of tracts close to the $80 \%$ MFI ratio cutoff that largely determines NMTC Program eligibility. Tracts immediately on either side of the cutoff are likely to be similar on both observed and unobserved dimensions, except that those right below the threshold are eligible for NMTC-subsidized investment while those right above are generally not eligible. Given this, any discontinuity in outcomes for tracts near the cutoff can be attributed to a causal effect of NMTC-subsidized investment.

The first-stage regression for the $\mathrm{RD}$ design can be written as

$$
N M T C_{i}=\alpha_{0}+\alpha_{1} L I C_{i}+f\left(m_{i}\right)+\mathbf{X}_{i} \boldsymbol{\Pi}+u_{i}
$$

\footnotetext{
${ }^{5}$ https://www.treasury.gov/press-center/press-releases/Pages/tg555.aspx
} 
and, substituting (2) into (1), the reduced-form regression is

$$
\Delta y_{i}=\gamma_{0}+\gamma_{1} L I C_{i}+\beta_{1} f\left(m_{i}\right)+\mathbf{X}_{i} \mathbf{\Phi}+v_{i}
$$

where $m_{i}$ is the fraction of households in tract $i$ with incomes below $80 \%$ of area MFI (the running variable), $L I C_{i}$ takes a value of 1 if tract $i$ qualifies as an LIC based on the threshold and a value of 0 otherwise, and $f\left(m_{i}\right)$ is a flexible polynomial in the running variable relative to the $80 \%$ cutoff.

For the RD design to be valid, any unmeasured determinants of outcomes must evolve smoothly through the MFI ratio cutoff that largely determines NMTC Program eligibility. One possible threat to this would be unobserved sorting of tracts around the cutoff. Such a selection problem is implausible in this context, as the data determining LIC status during the 2000s were released only after the NMTC Program was signed into law. Therefore, legislators could not have chosen the cutoffs to include some tracts and not others. Density tests and checks that baseline covariates evolve smoothly through the cutoff (discussed in more detail below) further suggest that no sorting occurred around the threshold.

Importantly, the RD estimates are local average treatment effects and may not generalize to neighborhoods beyond the subset of moderately poor tracts we consider in our analysis. The average median household income in 2000 among tracts with MFI ratios between 0.7 and 0.9 (which represent our main sample) is just over $\$ 36,000$. While the impacts of subsidized investment, and in particular subsidized retail food investment, in poorer communities is also of policy interest, the structure of the NMTC Program does not allow for causal identification of such impacts. Notably, though, the initial retail food environment was not dissimilar in neighborhoods more distressed than those we consider in our analysis. Based on data from the early to mid-2000s, $30 \%$ of tracts with MFI ratios between 0.7 and 0.8 were designated by the USDA as "low-income, low-access areas." ${ }^{6}$ This is in fact slightly greater than the fraction of tracts with MFI ratios below 0.7 that were classified as low-income, low-access areas (24\%). Similarly, the TDLinx data indicate that in 2004, the average number of supermarkets in tracts with MFI ratios between 0.7 and 0.9 and in tracts with MFI ratios between 0 and 0.7 were very similar at 0.79 and 0.81 ,

\footnotetext{
${ }^{6}$ The USDA made these designations in 2011 (after our sample period concludes) based on meeting NMTC eligibility rules and having at least $33 \%$ of the tract's population (or a minimum of 500 people) with low access to a supermarket (over one mile in an urban area and over ten miles in a rural area).
} 
respectively. This is consistent with the findings of Taylor and Villas-Boas (2016), who detect little difference in the proximity of poor vs. less poor households to supermarkets.

\section{Data}

\section{Data sources}

The data used in this study are derived from several sources. First, NMTC investment data come from the CDFI Fund at the U.S. Treasury. These data include the amount of the investment and some general information about the nature of the investment. They also include the exact location of the investment, which allowed us to assign each to a census tract. Our measure of NMTC investment, $N M T C_{i}$, is total amount of NMTC-subsidized investment (in millions of dollars) in each tract between 2003 (the start of the program) and 2009. ${ }^{7}$

Baseline neighborhood characteristics, $\mathbf{X}_{i}$, come from the 2000 Decennial Census. We include a host of census tract-level demographic variables (population, racial and ethnic composition, age distribution, educational attainment, foreign born status, public assistance receipt, public transit use, and household size) as well as housing variables (number of units, share occupied, share owner-occupied, share with a mortgage, median age of units, and median number of rooms). Variables determining LIC status (including the MFI ratio $m_{i}$ ) during the 2000s are also derived from 2000 Decennial Census data. LIC designations remained constant throughout our sample period.

Data on retail food establishments come from A.C. Nielsen's TDLinx. These annual data, which Hanner et al. (2015) and Hosken et al. (2016) describe in detail, include the universe of grocery stores, wholesale clubs, and convenience stores starting in $2004{ }^{8}$ The data include the exact location of each store, which we map to census tracts. Using proprietary methods, Nielsen also estimates the number of employees at stores. For the purposes of this paper, we follow Hosken et al. (2016) and define "supermarkets" as grocery stores as well as wholesale club stores. In our analysis of retail food entry and expansion, $\Delta y_{i}$ is measured as the change in the number of retail food establishments or employment between 2004 and 2009.

\footnotetext{
${ }^{7}$ Our data report year of investment, not project completion. To the extent that projects take more than a year to complete, our estimates will understate the impact of the program.

${ }^{8}$ While CDEs started receiving NMTC allocations in 2003, QLICIs only began in earnest after 2004. Hence, 2004 data are unlikely to capture any significant amount of NMTC investment.
} 
For information on food shopping and purchasing patterns, we use IRI's Consumer Network Database, which is derived from the National Consumer Panel (NCP). Households are recruited into the NCP and offered incentives to record all shopping trips and purchases, which they do with a handheld scanning device. The data also contain household characteristics, including census tract of residence. Certain demographic groups, and in particular younger respondents, respondents with children, and very low-income respondents, are less likely to report purchases consistently, but this is less of a problem when constructing our point-in-time measures (described in more detail below) than when trying to follow individual households over time (Muth et al. 2016). The IRI data's scope and detail allow us to richly characterize food shopping and purchasing behavior across neighborhoods.

\section{Sample and descriptive statistics}

For our main analysis, we focus on a narrow sliver of tracts around the $80 \%$ MFI ratio cutoff that largely determines eligibility for NMTC investment. Figure 1 shows the number of tracts in each percentage point bin of the MFI ratio between 0.6 and 1 , which encompasses the main sample $(0.7$ to 0.9 ) as well as larger windows considered in robustness tests. The dashed lines represent cubic fits through the points, separately estimated on either side of the 0.8 cutoff. As the figure makes clear, the density is smooth at the cutoff; that is, there is no bunching of tracts on either side of the threshold that might point to sorting around the cutoff that could invalidate the RD design. McCrary (2008) density tests confirm that there is no statistically significant discontinuity at the threshold.

In Table 1, we present descriptive statistics for tracts in the two ten percentage-point windows immediately on either side of the $80 \%$ MFI ratio cutoff. As Panel A suggests, tracts right below the cutoff are similar to tracts right above in terms of population, racial and ethnic composition, age distribution, foreign born status, educational attainment levels, welfare and transit use, and housing characteristics. As Panel B shows, the number of grocery stores and convenience stores in 2004 are also similar in tracts immediately on either side of the cutoff, as are the numbers of stores in tracts that neighbor those in our main sample (which we consider in a supplemental analysis on possible spillovers). ${ }^{9}$

\footnotetext{
${ }^{9}$ Using the Census' LODES data, we find no evidence of differential amounts of workplace employment on either side of the cutoff pre-NMTC, suggesting that tracts right above and below are not differentially likely to accommodate commercial investment for zoning or other reasons. Results are similar when we restrict the sample to tracts with any workers in 2002 .
} 
Figure 2 shows for several selected baseline (year 2000) census characteristics as well as baseline (year 2004) food retailing characteristics average values within each half percentage point bin of the running variable for the main sample of tracts (note that employment at convenience stores is not available in TDLinx). All the baseline covariates evolve smoothly through the cutoff, suggesting again that there were no pre-treatment differences among tracts immediately on either side of the threshold that might invalidate the RD design. ${ }^{10}$

\section{Results}

\section{First-stage estimates}

First, we establish that LIC status affected the amount of NMTC-subsidized investment in those communities. Graphical evidence that the MFI ratio threshold for LIC qualification generates a discontinuity in NMTC activity appears in Figure 3, which shows average cumulative NMTCsubsidized investment (in millions of dollars) between 2003 and 2009 in half percentage point bins of the running variable in a 20 percentage point window around the cutoff. In contrast to the baseline characteristics, each of which evolved smoothly through the cutoff, there is a sharp drop in NMTC investment at the 0.8 MFI ratio threshold.

The regression counterparts to Figure 3 (based on estimating equation (2)) appear in Panel A of Table 2. In each of the regressions, we use a cubic control function, which generally minimizes the AIC and BIC in these and subsequent reduced-form regressions, and include county fixed effects. In the even-numbered columns, we also control for the baseline demographic and housing variables listed in Panel A of Table 1. The standard errors shown in the table are clustered at the county level. F-statistics for the excluded instrument range from 10.3 to 11.5 , indicating that the instrument is reasonably strong.

The first-stage results suggest that LICs received on average about $\$ 900,000$ more in NMTC investment between 2003 and 2009 compared to tracts just above the threshold. This highly statistically significant effect is similar with and without tract-level demographic and housing controls, as expected if the likelihood of falling on either side of the cutoff is almost as good as random. The results are similar excluding county fixed effects and with alternative control functions (e.g., quadratic or quartic).

\footnotetext{
${ }^{10}$ Formal tests using the regression framework outlined in the Empirical Strategy section (using baseline characteristics as the outcomes) reveal no statistically significant discontinuities.
} 


\section{The effects of the NMTC on entry and expansion in the retail food industry}

To the extent that a portion of NMTC investment was going to the retail food industry, the program also generates quasi-experimental variation in food access in low-income neighborhoods. In Figure 4 and Table 2, we present results examining the effects of the NMTC on retail food establishment entry and expansion. Figure 4 illustrates the effects of LIC designation based on the MFI ratio on changes in the number of supermarkets, supermarket employment, and the number of convenience stores measured between 2004 and 2009. The dots show average growth in tracts within half percentage point bins of the running variable on either side of the cutoff. The figure points to greater growth in the number of supermarkets and supermarket employment among tracts just below the cutoff as compared to those just above the cutoff. Meanwhile, there is less of an apparent discontinuity in the change in the number of convenience stores at the MFI ratio cutoff.

In Panels B and C of Table 2, we attach numbers (and standard errors) to the discontinuities (or lack thereof) depicted in Figure 4. We show results for each outcome without and with controls for baseline tract characteristics. All regressions include county fixed effects. The first two columns in Panel B present reduced-form estimates of the relationship between LIC status and the change in the number of supermarkets between 2004 and 2009 (equation (3), where $\Delta y_{i}$ is defined as the difference between 2009 and 2004 in the number of supermarkets in tract $i$ ). The first two columns in Panel C present IV estimates of the effects of NMTC investment (in millions of dollars) between 2003 and 2009 on the same outcome, instrumenting NMTC investment with LIC status. Columns (3) and (4) report reduced-form and IV estimates for supermarket employment. Columns (5) and (6) present reduced-form and IV estimates for the number of convenience stores, which are less likely to have been subsidized directly by the NMTC and thus serve as something of a placebo.

The results point to a positive impact of the NMTC Program on growth in the grocery industry in affected communities. Regardless of specification, we find that LIC status is associated with a statistically significant 0.06 additional grocery stores on average; dividing this by the first-stage estimate in Panel A, we arrive at the IV estimate of the effect of \$1 million in NMTC investment on the number of grocery stores ( 0.07 in the model controlling for baseline tract characteristics). Multiplying this by the total amount of NMTC funding in the sample between 2003 and 2009 implies that during this period, the NMTC causally induced the entry of 25 grocery establishments, which is about $0.2 \%$ of the total stock of grocery stores in the sample. Assuming the fraction of 
NMTC projects in our sample that are supermarkets is the same as the fraction nationwide that are supermarkets (6-14\%), this would imply that $34-72 \%$ of those supermarkets would have located in a low-income neighborhood even in the absence of NMTC subsidies. The other $28-66 \%$ of the supermarkets may represent new retail food industry activity generated by the NMTC Program, but could also have been merely redirected from higher-income to lower-income areas.

In line with the results suggesting that NMTC-subsidized investment is associated with growth in the number of supermarkets, the results in columns (3) and (4) point to gains in supermarket employment in affected communities. The IV estimates imply that \$1 million in NMTC investment increases employment at supermarkets by eight workers. Obviously, NMTC investment occurs through a variety of channels outside retail food, so interpreting the program's relatively small impacts on the number of supermarkets and employment at supermarkets as its sole effects is misguided. Indeed, our estimates imply that if all program funds during the sample period had been dedicated to supermarkets, the NMTC would have led at least 179 supermarkets to enter lowincome areas in our sample.

Convenience stores are less likely to offer the affordable and nutritious food options that are perceived to be absent in many low-income neighborhoods. They also lack most of the features of supermarkets that make the latter an attractive investment for CDEs that leverage NMTC funds. As the final two columns of Table 2 show, NMTC investment has no statistically or economically meaningful effect on the number of convenience stores in low-income areas.

These estimates are robust to alternative specifications and samples. For example, the estimates change very little with alternative control function specifications (e.g., quadratic or quartic), when we condition on different sets of baseline neighborhood characteristics, or when we exclude county fixed effects. Linear probability models in which we evaluate whether the NMTC spurred supermarket entry in communities otherwise wholly lacking in supermarkets yield qualitatively similar, but less precisely estimated results. Dropping tracts that experienced particularly large gains in the supermarket industry also does not affect the estimates. We also find very similar effect sizes for windows around the threshold as small as ten and as large as 30 percentage points; in fact, the estimated reduced-form effect on supermarket growth is between 0.05 and 0.10 and consistently statistically significant at least at the $10 \%$ level for every sample of tracts within that range. In contrast, regardless of the sample used, the estimated reduced-form effect on convenience store growth is always very close to zero and never statistically significant. 
We also explored possible heterogeneous impacts of the program. In results not shown, we found larger impacts in tracts in MSAs relative to tracts outside of MSAs, but the differences in estimated effects were not statistically distinguishable. We also found that most of the effects are driven by relatively high-volume (more than $\$ 2$ million in annual sales) stores.

An important question is whether supermarket investment in LICs subsidized by the NMTC would have otherwise happened in other communities. To the extent displacement occurred in a localized fashion, the program may have had little effect on the retail food environment facing low-income individuals even if it did prompt new investment in targeted areas. To test this, we identified every tract that neighbors a tract in the main sample. We then determined the aggregate change in the number of retail food establishments and employment in these adjoining tracts. Using the same identification strategy as for our main results, we examined how LIC status (in the reduced-form) and NMTC investment (in the IV) for each tract in our sample affected outcomes in its neighbors. ${ }^{11}$

As shown in Table 3, we find mixed results for growth in the supermarket industry in neighboring tracts. The estimates point to a negative impact on the number of supermarkets, but a positive effect on supermarket employment. However, the estimates are not only imprecise, but are also very small in magnitude given they are off a much larger base (see Table 1). For example, there were 4.36 supermarkets in neighboring tracts in the sample on average in 2004, so the 0.05 supermarket decrease we find in response to \$1 million in NMTC investment is only about a $1 \%$ change. The effects for supermarket employment and the number of convenience stores are similarly small. Thus, we conclude that spillovers on the retail food environment in nearby neighborhoods were minimal.

\section{The effects of the NMTC on food shopping and purchasing patterns}

NMTC-subsidized investment could plausibly affect measured food shopping patterns in recipient communities in several ways. First, to the extent that subsidized investment improved the circumstances of existing residents (potentially by providing new job opportunities) or attracted

\footnotetext{
${ }^{11}$ For example, the reduced form is $\Delta y_{i}^{N}=\gamma_{0}+\gamma_{1} L I C_{i}+\beta_{1} f\left(m_{i}\right)+\mathbf{X}_{i} \boldsymbol{\Phi}+v_{i}$, where $\Delta y_{i}^{N}$ is the change in the number of retail food establishments or employment in all tracts neighboring tract $i$, and all other variables are defined as before. We lose ten tracts (two below the 0.8 threshold and eight above) that have no neighbors as a result of being entirely surrounded by water or only abutting another country; the different samples are the source of the slight discrepancies in first-stage results in Tables 2 and 3.
} 
new, relatively affluent residents to affected neighborhoods, it would likely have the effect of increasing the relative quantity of healthy food purchased (Cutler and Lleras-Muney 2010).

Additionally, some NMTC funds were used to subsidize the establishment or expansion of health care facilities in low-income neighborhoods. The NMTC Coalition (2014) reported that between 2003 and 2012, 9.6\% of NMTC projects were in the health care industry. If new health care centers provided any outreach or counseling to residents about diet choices, they would also likely serve to increase the relative amount of healthy food purchased. ${ }^{12}$

Given the previous results, a final channel by which NMTC investment could affect food purchasing patterns would be through its effects on food access. We test this first by examining the frequency of shopping trips to or dollars spent at supermarkets and convenience stores among households in eligible communities. Next, we examine the composition of food purchases among households in eligible communities. We use household-level survey and scanner data from IRI to conduct these tests. Unfortunately, sample sizes in the IRI are substantially smaller prior to 2008, so we cannot compare changes in outcomes within tracts or within households before and after NMTC-subsidized investment using these data. We instead focus on differences in levels in posttreatment outcomes between households located in tracts immediately on either side of the $80 \%$ MFI threshold (i.e., within the same 20 percentage point window used in the previous regressions). To the extent that households living in neighborhoods within a narrow window around the cutoff are not systematically different, using levels as opposed to changes should not introduce bias. However, the estimates will reflect variation in shopping and purchasing patterns driven by changes in the composition of residents as well as changes in the behavior of existing residents in the wake of LIC designation. To partially address the question of how compositional changes might be affecting the results, we present estimates based on outcomes measured at the household level, where we can additionally control for individual household characteristics.

We use outcomes measured in 2012, which has the benefit of allowing for some lag (albeit a modest one) in the impact of NMTC-subsidized on food shopping and purchasing behavior. It also maximizes the number of survey respondents with usable data, although we still are obliged to limit the sample to 30,306 households who live in tracts with MFI ratios within 20 percentage

\footnotetext{
${ }^{12}$ Another possible channel by which the NMTC could affect food shopping and purchasing in affected communities is through its effects on restaurant entry. However, given their higher failure rate, restaurants represent less attractive investments for CDEs. Between 2003 and 2012, only $0.8 \%$ of all NMTC projects were restaurants (NMTC Coalition 2014).
} 
points of the $80 \%$ cutoff and for whom we have sufficient information to measure food shopping behavior. ${ }^{13}$ The household characteristics available in the IRI data are also only reliable beginning in 2012, as IRI overwrote values from previous years as more recent survey information became available. For the IRI outcomes, we show only reduced-form results of the effects of LIC designation on outcomes, and we again cluster standard errors at the county level. ${ }^{14}$

In Panel A of Table 4, we present results for the number of supermarket trips per month (first two columns) and convenience store trips per month (last two columns) using our RD sample. The first and third columns show estimates controlling for the cubic control function, county fixed effects, and baseline (year 2000) tract demographic and housing characteristics; the second and fourth columns present estimates additionally controlling for individual household characteristics (specifically, household size, household income, race, ethnicity, number and ages of children in the household, educational attainment levels, employment and occupation dummies, marital status, and whether the household rents or owns their home). The controls for household characteristics help to address any differences in the composition of households across areas, including those driven by NMTC-induced changes in neighborhood amenities.

As is clear in Panel A, there is little evidence that LIC status is associated with a difference in the average frequency with which people living in the tract visit a supermarket. Conditioning on baseline tract-level characteristics, we find that LIC status is associated with 0.006 fewer supermarket trips per month among households on average. Adding household-specific characteristics to the regression attenuates the effect to 0.002 fewer supermarket trips per month on average. Both point estimates are within one-twentieth of one percent of the typical 4.2 supermarket visits per month among households in our sample. In contrast, the results in columns (3) and (4) of Panel A suggest that households in tracts eligible for NMTC investment make about 0.18 fewer visits per month to convenience stores on average, a statistically significant change that corresponds to a $46 \%$ reduction in the frequency of convenience store visits. This change is similar regardless of whether we control for household characteristics.

\footnotetext{
${ }^{13}$ To ensure the largest and most representative population possible, we calculate food shopping and purchasing statistics for all households in the IRI data, removing only probabilistic outliers (as in Volpe et al. (2013)).

${ }^{14}$ The reduced form is $y_{h i}^{2012}=\gamma_{0}+\gamma_{1} L I C_{i}+\beta_{1} f\left(m_{i}\right)+\mathbf{X}_{i} \boldsymbol{\Phi}+\mathbf{Z}_{h} \boldsymbol{\Psi}+v_{h i}$, where $y_{h i}^{2012}$ is the outcome for household $h$ in tract $i$ measured in 2012, $\mathbf{Z}_{h}$ is a vector of household $h$ 's characteristics, and all other variables are defined as before. In the spillover analysis that follows, we include outcomes and characteristics for households in tract $i$ and in all tracts neighboring tract $i$. We do not weight the regressions using IRI's projection weights, which are not designed to ensure representativeness for the particular geography on which we focus. For most outcomes, the results are not qualitatively different when we weight the regressions.
} 
These results hint that households in affected communities, while not increasing the frequency of supermarket shopping trips, may be shifting some of their purchases from convenience stores to supermarkets. The results in Panel B of Table 4 provide one indication that this could in fact be occurring. Relative to households in barely ineligible neighborhoods, households in NMTCeligible neighborhoods spend $\$ 4$ more at supermarkets per month on average. Meanwhile, households spend $\$ 3$ less at convenience stores per month on average. While neither estimate is statistically significant, the observed pattern of spending is consistent with some shifting of purchases away from convenience stores and toward supermarkets.

If households in affected neighborhoods are reallocating purchases toward supermarkets, we might expect it to show up in food expenditure patterns, and specifically the relative amount of nutritious food purchased. In Panel C of Table 4, we show results for the healthfulness of food expenditures by households. We follow Volpe et al. (2013) to construct scores that capture the extent to which a household's expenditures on food deviate from the recommendations of the USDA's Center for Nutrition Policy and Promotion (CNPP). The CNPP determines food plans for households that help ensure they meet the USDA's Dietary Guidelines for Americans. These recommendations vary with household composition (specifically, the presence and age of adult males and females in the household, as well as the presence and age of children in the household), which we adjust for using information in the IRI data. Based on these household recommendations and the observed expenditures by households on 23 food categories, we assign each household in the data a score that reflects the degree to which that household adhered to the USDA recommendations. The score is calculated as

$$
\text { BasketScore }_{j h}^{A}=\left[\sum_{c}\left(\exp _{j h c}-\operatorname{rec}_{h c}\right)^{2}\right]^{-1},
$$

where the subscript $j$ denotes the household, $h$ the household type (the basis for the USDA's recommended food expenditure shares), and $c$ the food category, and where $\exp$ is the observed expenditure share of the household and rec is the share recommended under the USDA guidelines for a household of that type. ${ }^{15}$

This measure penalizes households for expenditures above or below the recommended amount in any particular category. We also show results using a measure calculated as

\footnotetext{
${ }^{15}$ We assign an expenditure share of zero when we do not observe any purchases of food in a particular category, but arrive at qualitatively similar results when we do not assume that households report all purchases.
} 


$$
\text { BasketScore }_{j h}^{B}=\left\{\begin{array}{c}
{\left[\sum_{c \in \text { healthful }}\left(\exp _{j h c}-r e c_{h c}\right)^{2} \mid \exp _{j h c}<r e c_{h c}\right]+} \\
{\left[\sum_{c \notin \text { ealthful }}\left(\exp _{j h c}-r e c_{h c}\right)^{2} \mid \exp _{j h c}>r e c_{h c}\right]}
\end{array}\right\}^{-1},
$$

which does not penalize households for too much of a healthy purchase or too little of an unhealthy purchase. ${ }^{16}$

The mean BasketScore ${ }_{j h}^{A}$ (BasketScore ${ }_{j h}^{B}$ ) in 2012 among households in the ten percentage point window below the 0.8 cutoff was 5.8 (5.9), and that for households in the ten percentage point window above the 0.8 cutoff was 5.9 (6.1). In regressions akin to (3) where the outcomes are the 2012 Basket Scores, we find no discernable difference in scores among households on either side of the threshold; as shown in Table 4, focusing on BasketScore $e_{j h}^{A}$ and including both neighborhood and household controls, households in a NMTC-eligible neighborhood had scores 0.026 higher than those in ineligible neighborhoods, a difference that is both economically small and statistically insignificant. Even the upper bound of the $95 \%$ confidence interval around the point estimate (a 0.19 higher score in NMTC-eligible communities) would only represent a small (9\% of a standard deviation) difference in BasketScore ${ }_{j h}^{A}$. As shown in columns (3) and (4) of Panel C, the results are qualitatively similar when we use BasketScore $e_{j h}^{B}$, which does not penalize too little (much) of an unhealthy (healthy) purchase. We similarly find null results with alternative specifications and samples. ${ }^{17}$

Given we are isolating attention to households in directly affected tracts, we may be understating the impacts of the program on food shopping and purchasing patterns. To examine this, we add to the sample all households in tracts adjacent to those in the main sample and test whether LIC status in a tract in the main sample affects outcomes among households over a broader geographic area. As the results in the final four columns of Table 4 show, we find no economically or statistically significant impacts on shopping habits or basket scores among households in this expanded sample.

Overall, our findings suggest that, to the extent that the NMTC is inducing supermarket entry in low-income neighborhoods, the resulting increase in food access is not having large effects on

\footnotetext{
${ }^{16} \mathrm{We}$ also explored simpler, but less concise measures such as the absolute amount and share of expenditures on fresh fruit and vegetables, or on salty snacks and desserts. The estimated impacts on these measures were similarly small and statistically insignificant.

${ }^{17}$ In supplementary analyses in which we stratify households by shopping frequency, we find that the positive effects on dollars spent at supermarkets is more pronounced for low-frequency shoppers. However, there are no statistically or economically meaningful differences in basket scores for either low- or high-frequency shoppers.
} 
food purchasing patterns. Notably, though, while we find little evidence of business displacement from neighboring tracts, we cannot completely rule out that the NMTC is prompting only minor locational shifts for many grocery stores that take up the subsidy, leading to large changes in the menu of food buying options for only a small segment of the population. Additionally, our results only capture changes in food purchasing behavior within communities in the short-run, and the impacts of improved access to healthy food on buying patterns may take longer than a few years to materialize.

\section{Conclusion}

This paper examines the effects of the U.S. federal government's NMTC Program on the retail food environment as well as food shopping and purchasing patterns in low-income neighborhoods. In order to identify the impacts of the program, we take advantage of a discontinuity in NMTC funding generated by the formula used to determine the eligibility of census tracts for subsidized investment under the program.

Our results suggest that the NMTC has had modest positive impacts on supermarket entry in communities close to the income threshold that determines eligibility for the program. This is not to suggest that the NMTC necessarily increased the number of supermarkets on aggregate, as many of the supermarkets that located in these communities with the help of preferable financing terms made possible by the NMTC might have otherwise located elsewhere. Nonetheless, the results suggest that supply-side subsidies can be a useful, albeit potentially expensive, tool to at least redirect investment into certain targeted areas.

Whether this is desirable from a policy perspective depends on the extent to which subsidized investments have greater social returns in targeted neighborhoods as compared to other neighborhoods in which they might have otherwise located. The potential positive diet and health consequences of new grocery stores in low-income areas are one channel by which such social returns could be realized. However, at least in communities near the threshold that determines NMTC Program eligibility, our results suggest that supermarkets, along with any other amenities or changes in neighborhood composition that come with NMTC investment, do not have measurable effects on households' food buying patterns, at least in the short run. 


\section{References}

Abravanel M, Pindus N, Theodos B, et al. (2013) New Markets Tax Credit Program Evaluation. Urban Institute, Metropolitan Housing and Communities Policy Center.

Aussenberg R (2014) SNAP and Related Nutrition Provisions of the 2014 Farm Bill (P.L. 11379). Congressional Research Service Report 7-5700, R43332.

Bitler M and Haider S (2011) An Economic View of Food Deserts in the United States. Journal of Policy Analysis and Management 30(1): 153-176.

CDC (2011) State Initiatives for Supporting Healthier Food Retail: An Overview of the National Landscape. Division of Nutrition, Physical Activity, and Obesity, Report CS226271.

Cummins S, Flint E and Matthews S (2014) New Neighborhood Grocery Store Increased Awareness of Food Access But Did Not Alter Dietary Habits or Obesity. Health Affairs 33(2): 283-291.

Cutler D and Lleras-Muney A (2010) Understanding Differences in Health Behaviors by Education. Journal of Health Economics 29(1): 1-28.

Elbel B, Moran A, Dixon B, et al. (2015) Assessment of a Government-Subsidized Supermarket in a High-Need Area on Household Food Availability and Children's Dietary Intakes. Public Health Nutrition 18(15): 2881-2890.

Food Marketing Institute (1998) Urban Supermarkets. Washington, DC.

Freedman M (2012) Teaching New Markets Old Tricks: The Effects of Subsidized Investment in Low-Income Neighborhoods. Journal of Public Economics 96(11-12): 1000-1014.

Freedman M (2015) Place-Based Programs and the Geographic Dispersion of Employment. Regional Science and Urban Economics 53: 1-19.

Handbury J, Rahkovsky I and Schnell M (2016) Is the Focus on Food Deserts Fruitless? Retail Access and Food Purchases across the Socioeconomic Spectrum. University of Pennsylvania.

Hanner D, Hosken D, Olson L, et al. (2015) Dynamics in a Mature Industry: Entry, Exit, and Growth of Big-Box Grocery Retailers. Journal of Economics and Management Strategy 24(1): $22-46$.

Harger K and Ross A (2016) Do Capital Tax Incentives Attract New Businesses? Evidence across Industries from the New Markets Tax Credit. Journal of Regional Science 56(5): 733753. 
Hosken D, Olson L and Smith L (2016) Can Entry or Exit Event Studies Inform Horizontal Merger Analysis? Evidence from Grocery Retailing. Economic Inquiry 54(1): 342-360.

McCrary J (2008) Manipulation of the Running Variable in the Regression Discontinuity Design: A Density Test. Journal of Econometrics 142(2): 698-714.

Muth M, Sweitzer M, Brown D, et al. (2016) Understanding IRI Household-Based and StoreBased Scanner Data. USDA ERS Technical Bulletin 1942.

NMTC Coalition (2014) A Decade of the New Markets Tax Credit: An Economic Impact Analysis. December.

Reinvestment Fund (2011) New Markets Tax Credits and Urban Supermarkets. In: Financing Healthy Food Options: Implementation Handbook. U.S. Department of Treasury.

Short A, Guthman J and Raskin S (2007) Food Deserts, Oases, or Mirages? Small Markets and Community Food Security in the San Francisco Bay Area. Journal of Planning Education and Research 26(3): 352-364.

U.S. GAO (2010) New Markets Tax Credit: The Credit Helps Fund a Variety of Projects in LowIncome Communities, But Could Be Simplified. GAO-10-334.

Ver Ploeg M, Breneman V, Farrigan T, et al. (2009) Access to Affordable and Nutritious Food: Measuring and Understanding Food Deserts and Their Consequences. Report to Congress, Economic Research Service.

Volpe R, Okrent A and Leibtag E (2013) The Effect of Supercenter-Format Stores on the Healthfulness of Consumers' Grocery Purchases. American Journal of Agricultural Economics 95(3): 568-589.

Weatherspoon D, Oehmke J, Dembele A, et al. (2013) Price and Expenditure Elasticities for Fresh Fruits in an Urban Food Desert. Urban Studies 50(1): 88-106.

Wrigley N (2002) Food Deserts in British Cities: Policy Context and Research Priorities. Urban Studies 39(11): 2029-2040.

Wrigley N, Warm D and Margetts B (2003) Deprivation, Diet, and Food-Retail Access: Findings from the Leeds 'Food Deserts' Study. Environment and Planning A 35(1): 151-188. 
Table 1. Descriptive statistics for tracts near the 0.8

MFI threshold.

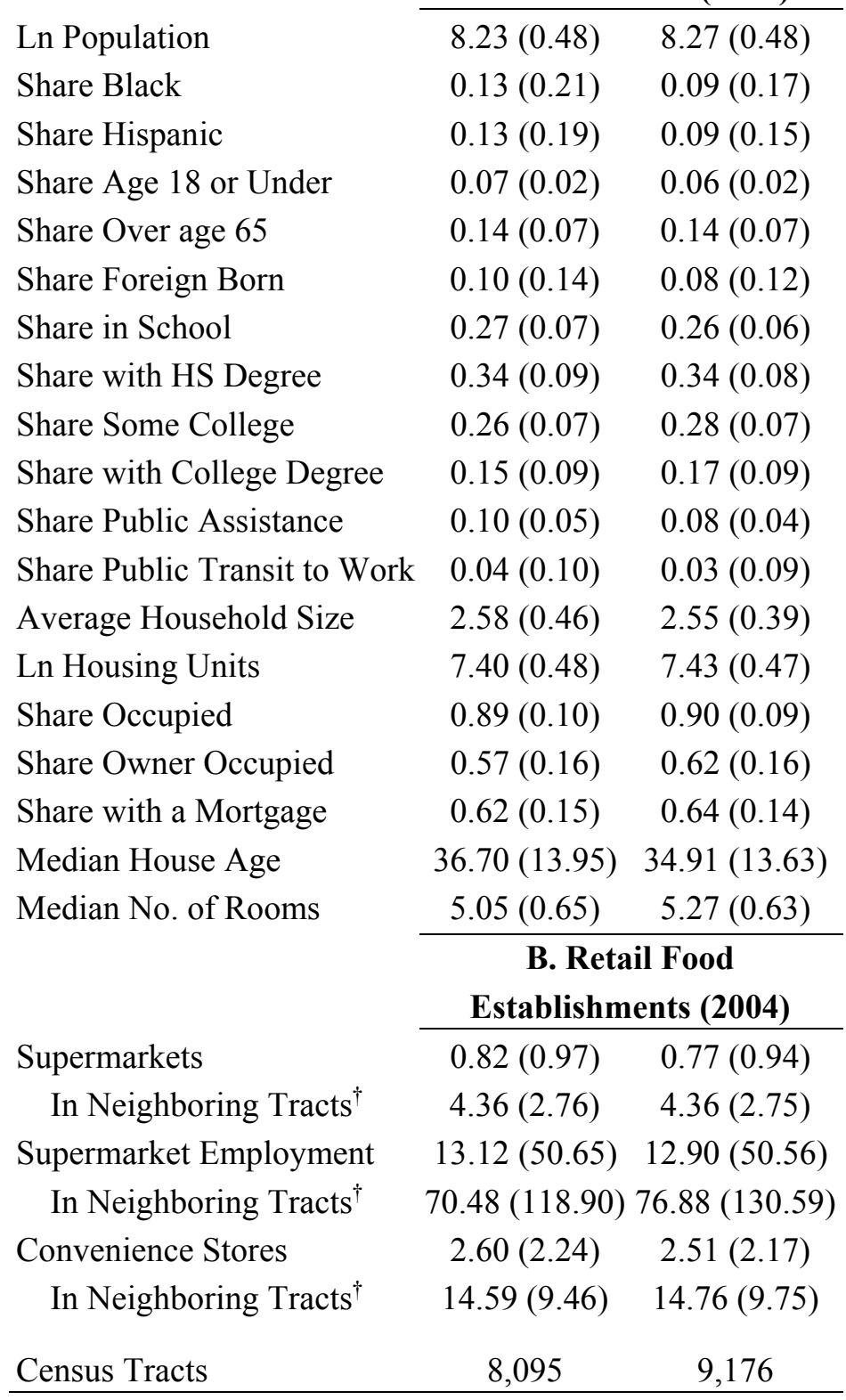

$\frac{\text { MFI Ratio Bin }}{20.7,0.8] \quad(0.8,0.9]}$

A. Demographic \& Housing Characteristics (2000)

$0.13(0.21) \quad 0.09(0.17)$

$0.09(0.15)$

$0.07(0.02) \quad 0.06(0.02)$

$0.10(0.14) \quad 0.08(0.12)$

$0.26(0.06)$

$0.34(0.09) \quad 0.34(0.08)$

$0.28(0.07)$

$0.10(0.05) \quad 0.08(0.04)$

$0.04(0.10) \quad 0.03(0.09)$

$2.58(0.46)-2.55(0.39)$

$7.40(0.48) \quad 7.43(0.47)$

$0.57(0.16) \quad 0.62(0.16)$$$
36.70(13.95) \quad 34.91(13.63)
$$

B. Retail Food

$0.82(0.97) \quad 0.77(0.94)$

Notes: Data from Decennial Census (Panel A) and TDLinx (Panel B). Standard deviations in parentheses. ${ }^{\dagger}$ Ten tracts have no neighbors. 
Table 2. First-stage, reduced-form, and IV estimates for retail food establishments.

\begin{tabular}{|c|c|c|c|c|c|c|}
\hline & $(1)$ & $(2)$ & (3) & (4) & $(5)$ & $(6)$ \\
\hline \multirow{5}{*}{ LIC Status } & \multicolumn{6}{|c|}{ A. First-Stage Estimates } \\
\hline & \multicolumn{6}{|c|}{ NMTC Investment (\$ Mil.) } \\
\hline & $0.957 * * *$ & $0.850 * * *$ & $0.957 * * *$ & $0.850 * * *$ & $0.957 * * *$ & $0.850 * * *$ \\
\hline & $(0.282)$ & $(0.265)$ & $(0.282)$ & $(0.265)$ & $(0.282)$ & $(0.265)$ \\
\hline & \multicolumn{6}{|c|}{ B. Reduced-Form Estimates } \\
\hline & \multirow{2}{*}{\multicolumn{2}{|c|}{$\begin{array}{c}\text { Supermarket } \\
\text { Establishments }\end{array}$}} & \multirow{2}{*}{\multicolumn{2}{|c|}{$\begin{array}{l}\text { Supermarket } \\
\text { Employment }\end{array}$}} & \multirow{2}{*}{\multicolumn{2}{|c|}{$\begin{array}{c}\text { Conv. Store } \\
\text { Establishments }\end{array}$}} \\
\hline & & & & & & \\
\hline \multirow[t]{5}{*}{ LIC Status } & $0.057 * *$ & $0.059 * *$ & $7.192 * *$ & $6.891 * *$ & -0.028 & -0.024 \\
\hline & $(0.026)$ & $(0.026)$ & $(2.819)$ & $(2.855)$ & $(0.047)$ & $(0.047)$ \\
\hline & \multicolumn{6}{|c|}{ C. IV Estimates } \\
\hline & \multirow{2}{*}{\multicolumn{2}{|c|}{$\begin{array}{l}\text { Supermarket } \\
\text { Establishments }\end{array}$}} & \multirow{2}{*}{\multicolumn{2}{|c|}{$\begin{array}{l}\text { Supermarket } \\
\text { Employment }\end{array}$}} & \multirow{2}{*}{\multicolumn{2}{|c|}{$\begin{array}{c}\text { Conv. Store } \\
\text { Establishments }\end{array}$}} \\
\hline & & & & & & \\
\hline \multirow[t]{2}{*}{ NMTC Investment (\$ Mil.) } & $0.059 *$ & $0.069 *$ & $7.512 * *$ & $8.102 *$ & -0.029 & -0.028 \\
\hline & $(0.030)$ & $(0.035)$ & $(3.739)$ & $(4.238)$ & $(0.049)$ & $(0.055)$ \\
\hline Cubic Control Function & $\checkmark$ & $\checkmark$ & $\checkmark$ & $\checkmark$ & $\checkmark$ & $\checkmark$ \\
\hline County Fixed Effects & $\checkmark$ & $\checkmark$ & $\checkmark$ & $\checkmark$ & $\checkmark$ & $\checkmark$ \\
\hline $\begin{array}{l}\text { Tract Demographic \& } \\
\text { Housing Controls }\end{array}$ & & $\checkmark$ & & $\checkmark$ & & $\checkmark$ \\
\hline $\begin{array}{l}\text { Kleibergen-Paap rk Wald } \\
\text { F Statistic }\end{array}$ & 11.543 & 10.333 & 11.543 & 10.333 & 11.543 & 10.333 \\
\hline Observations & \multicolumn{6}{|c|}{17,271} \\
\hline
\end{tabular}

Notes: Standard errors (in parentheses) are adjusted for heteroskedasticity and clusters at the county level. Significant at the $* 10 \%$ level, $* * 5 \%$ level, and $* * * 1 \%$ level. 
Table 3. First-stage, reduced-form, and IV estimates for retail food establishments in neighboring tracts.

\begin{tabular}{|c|c|c|c|c|c|c|}
\hline & $(1)$ & $(2)$ & (3) & (4) & $(5)$ & $(6)$ \\
\hline & \multicolumn{6}{|c|}{ A. First-Stage Estimates } \\
\hline \multirow{4}{*}{ LIC Status } & \multicolumn{6}{|c|}{ NMTC Investment (\$ Mil.) } \\
\hline & $0.957 * * *$ & $0.855 * * *$ & $0.957 * * *$ & $0.855^{* * *}$ & $0.957 * * *$ & $0.855 * * *$ \\
\hline & $(0.282)$ & $(0.267)$ & $(0.282)$ & $(0.267)$ & $(0.282)$ & $(0.267)$ \\
\hline & \multicolumn{6}{|c|}{ B. Reduced-Form Estimates } \\
\hline & \multirow{2}{*}{\multicolumn{2}{|c|}{$\begin{array}{l}\text { Supermarket } \\
\text { Establishments }\end{array}$}} & \multirow{2}{*}{\multicolumn{2}{|c|}{$\begin{array}{l}\text { Supermarket } \\
\text { Employment }\end{array}$}} & \multirow{2}{*}{\multicolumn{2}{|c|}{$\begin{array}{c}\text { Conv. Store } \\
\text { Establishments }\end{array}$}} \\
\hline & & & & & & \\
\hline \multirow[t]{5}{*}{ LIC Status } & -0.046 & -0.041 & 5.575 & 6.255 & 0.031 & 0.027 \\
\hline & $(0.069)$ & $(0.068)$ & $(8.316)$ & $(8.315)$ & $(0.118)$ & $(0.118)$ \\
\hline & \multicolumn{6}{|c|}{ C. IV Estimates } \\
\hline & \multirow{2}{*}{\multicolumn{2}{|c|}{$\begin{array}{c}\text { Supermarket } \\
\text { Establishments }\end{array}$}} & \multirow{2}{*}{\multicolumn{2}{|c|}{$\begin{array}{l}\text { Supermarket } \\
\text { Employment }\end{array}$}} & \multirow{2}{*}{\multicolumn{2}{|c|}{$\begin{array}{c}\text { Conv. Store } \\
\text { Establishments }\end{array}$}} \\
\hline & & & & & & \\
\hline \multirow[t]{2}{*}{ NMTC Investment (\$ Mil.) } & -0.048 & -0.048 & 5.824 & 7.319 & 0.032 & 0.031 \\
\hline & $(0.073)$ & $(0.081)$ & (8.934) & $(10.142)$ & $(0.123)$ & $(0.138)$ \\
\hline Cubic Control Function & $\checkmark$ & $\checkmark$ & $\checkmark$ & $\checkmark$ & $\checkmark$ & $\checkmark$ \\
\hline County Fixed Effects & $\checkmark$ & $\checkmark$ & $\checkmark$ & $\checkmark$ & $\checkmark$ & $\checkmark$ \\
\hline $\begin{array}{c}\text { Tract Demographic \& } \\
\text { Housing Controls }\end{array}$ & & $\checkmark$ & & $\checkmark$ & & $\checkmark$ \\
\hline $\begin{array}{l}\text { Kleibergen-Paap rk Wald } \\
\text { F Statistic }\end{array}$ & 11.538 & 10.275 & 11.538 & 10.275 & 11.538 & 10.275 \\
\hline Observations & \multicolumn{6}{|c|}{17,261} \\
\hline
\end{tabular}

Notes: Ten tracts have no neighbors. Standard errors (in parentheses) are adjusted for heteroskedasticity and clusters at the county level. Significant at the * $10 \%$ level, $* * 5 \%$ level, and $* * * 1 \%$ level. 
Table 4. Reduced-form estimates for food shopping and purchasing patterns.

\begin{tabular}{|c|c|c|c|c|c|c|c|c|}
\hline & $(1)$ & $(2)$ & $(3)$ & $(4)$ & $(5)$ & $(6)$ & $(7)$ & $(8)$ \\
\hline & \multicolumn{4}{|c|}{ Main Sample } & \multicolumn{4}{|c|}{ Including Neighboring Tracts } \\
\hline & \multicolumn{8}{|c|}{ A. Trips per Month } \\
\hline & \multicolumn{2}{|c|}{ Supermarkets } & \multicolumn{2}{|c|}{ Conv. Stores } & \multicolumn{2}{|c|}{ Supermarkets } & \multicolumn{2}{|c|}{ Conv. Stores } \\
\hline \multirow[t]{4}{*}{ LIC Status } & -0.006 & -0.002 & $-0.180 *$ & $-0.184 *$ & 0.040 & 0.035 & -0.055 & -0.052 \\
\hline & $(0.172)$ & $(0.170)$ & $(0.105)$ & $(0.104)$ & $(0.108)$ & $(0.106)$ & $(0.047)$ & $(0.047)$ \\
\hline & \multicolumn{8}{|c|}{ B. Dollars Spent per Month } \\
\hline & \multicolumn{2}{|c|}{ Supermarkets } & \multicolumn{2}{|c|}{ Conv. Stores } & \multicolumn{2}{|c|}{ Supermarkets } & \multicolumn{2}{|c|}{ Conv. Stores } \\
\hline \multirow[t]{4}{*}{ LIC Status } & 3.999 & 4.337 & -2.616 & -2.619 & -4.413 & -4.588 & -0.203 & -0.160 \\
\hline & $(7.552)$ & $(7.254)$ & $(1.881)$ & $(1.862)$ & $(4.667)$ & $(4.439)$ & $(0.846)$ & $(0.839)$ \\
\hline & \multicolumn{8}{|c|}{ C. Food Purchases } \\
\hline & \multicolumn{2}{|c|}{ BasketScore $^{\mathrm{A}}$} & \multicolumn{2}{|c|}{ BasketScore $^{\mathrm{B}}$} & \multicolumn{2}{|c|}{ BasketScore $^{\mathrm{A}}$} & \multicolumn{2}{|c|}{ BasketScore $^{\mathrm{B}}$} \\
\hline \multirow[t]{2}{*}{ LIC Status } & 0.017 & 0.026 & 0.082 & 0.083 & 0.033 & 0.040 & 0.013 & 0.019 \\
\hline & $(0.088)$ & $(0.084)$ & $(0.093)$ & $(0.089)$ & $(0.051)$ & $(0.049)$ & $(0.054)$ & $0.053)$ \\
\hline Cubic Control Function & $\checkmark$ & $\checkmark$ & $\checkmark$ & $\checkmark$ & $\checkmark$ & $\checkmark$ & $\checkmark$ & $\checkmark$ \\
\hline County Fixed Effects & $\checkmark$ & $\checkmark$ & $\checkmark$ & $\checkmark$ & $\checkmark$ & $\checkmark$ & $\checkmark$ & $\checkmark$ \\
\hline $\begin{array}{l}\text { Tract Demographic \& } \\
\text { Housing Controls }\end{array}$ & $\checkmark$ & $\checkmark$ & $\checkmark$ & $\checkmark$ & $\checkmark$ & $\checkmark$ & $\checkmark$ & $\checkmark$ \\
\hline $\begin{array}{l}\text { Controls for Household } \\
\text { Characteristics }\end{array}$ & & $\checkmark$ & & $\checkmark$ & & $\checkmark$ & & $\checkmark$ \\
\hline Observations & \multicolumn{4}{|c|}{30,306} & \multicolumn{4}{|c|}{82,366} \\
\hline
\end{tabular}

Notes: Standard errors (in parentheses) are adjusted for heteroskedasticity and clusters at the county level. Significant at the $* 10 \%$ level, $* * 5 \%$ level, and $* * * 1 \%$ level. 


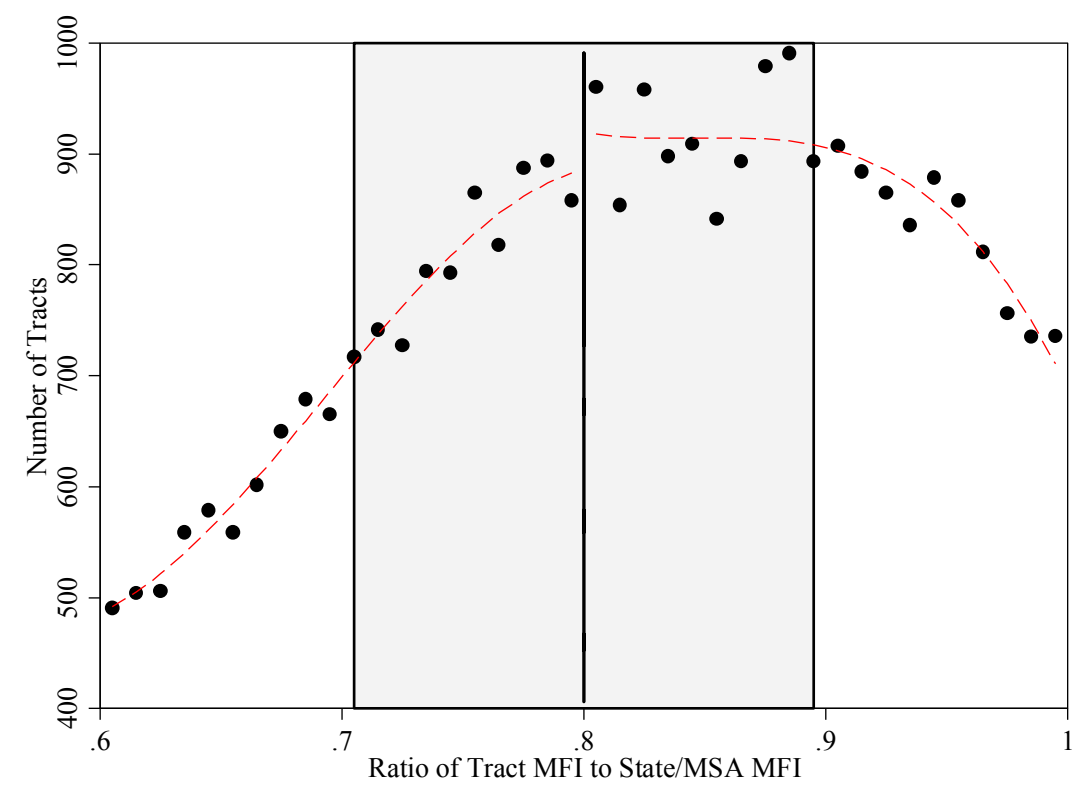

Figure 1. Density of tracts around the $80 \%$ MFI ratio cutoff. Source: Decennial Census.
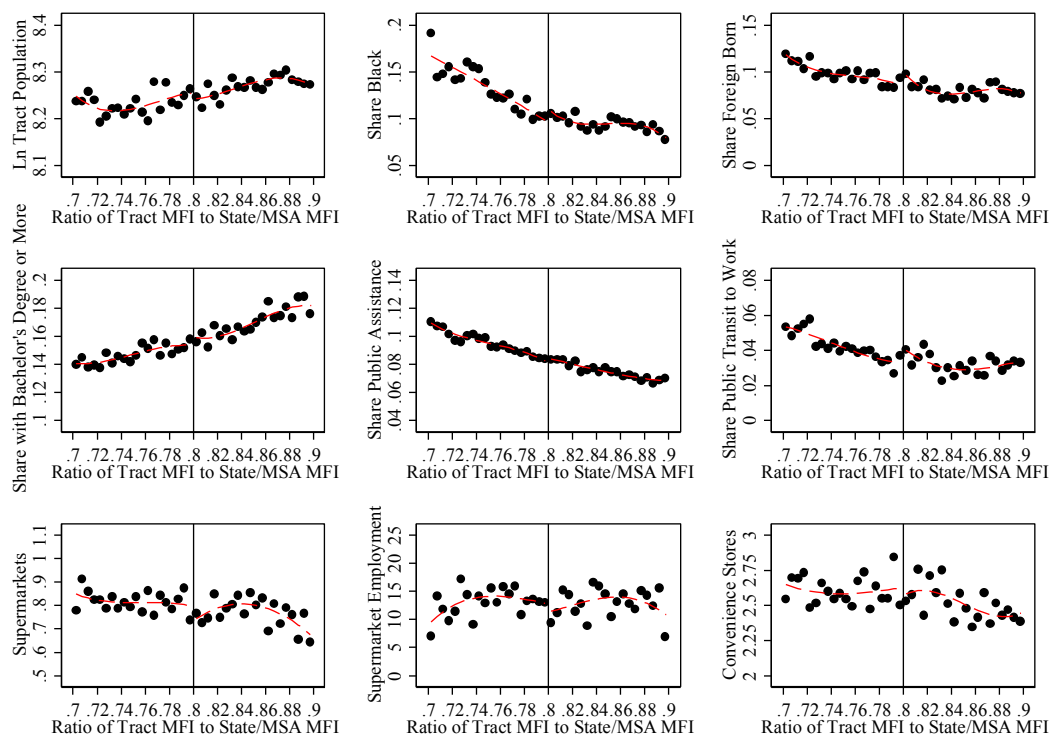

Figure 2. Selected baseline tract characteristics at the LIC MFI ratio eligibility threshold. Source: Decennial Census and TDLinx. 


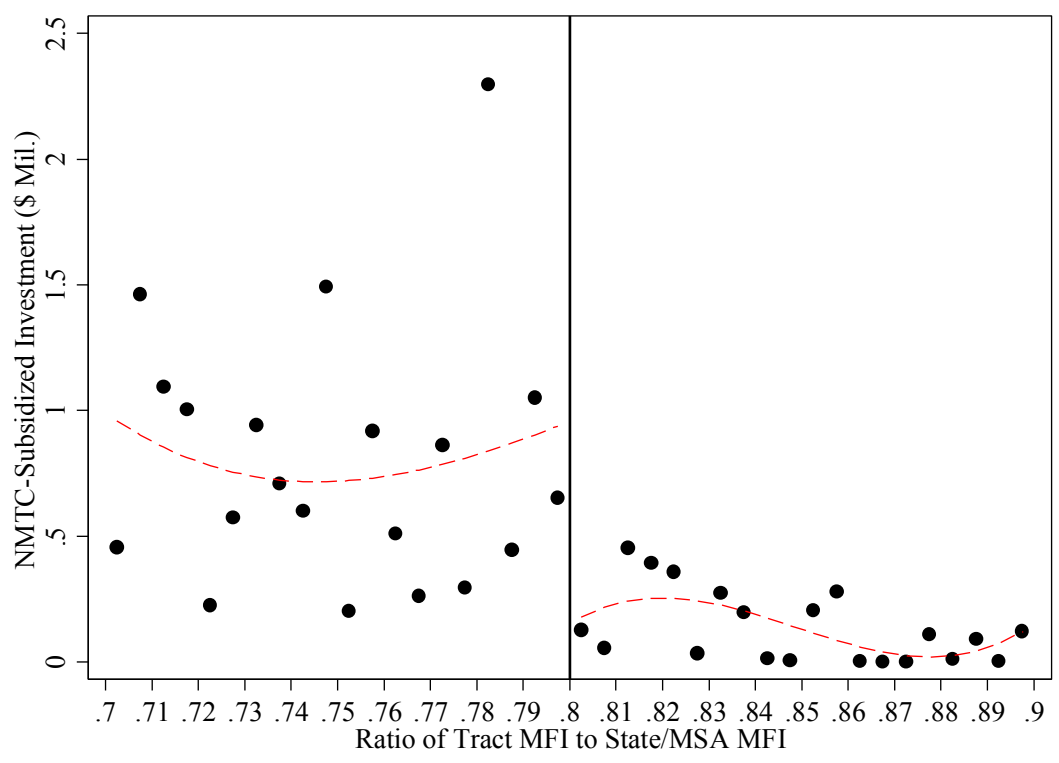

Figure 3. NMTC investment at the LIC MFI ratio eligibility threshold. Source: Decennial Census and CDFI Fund.
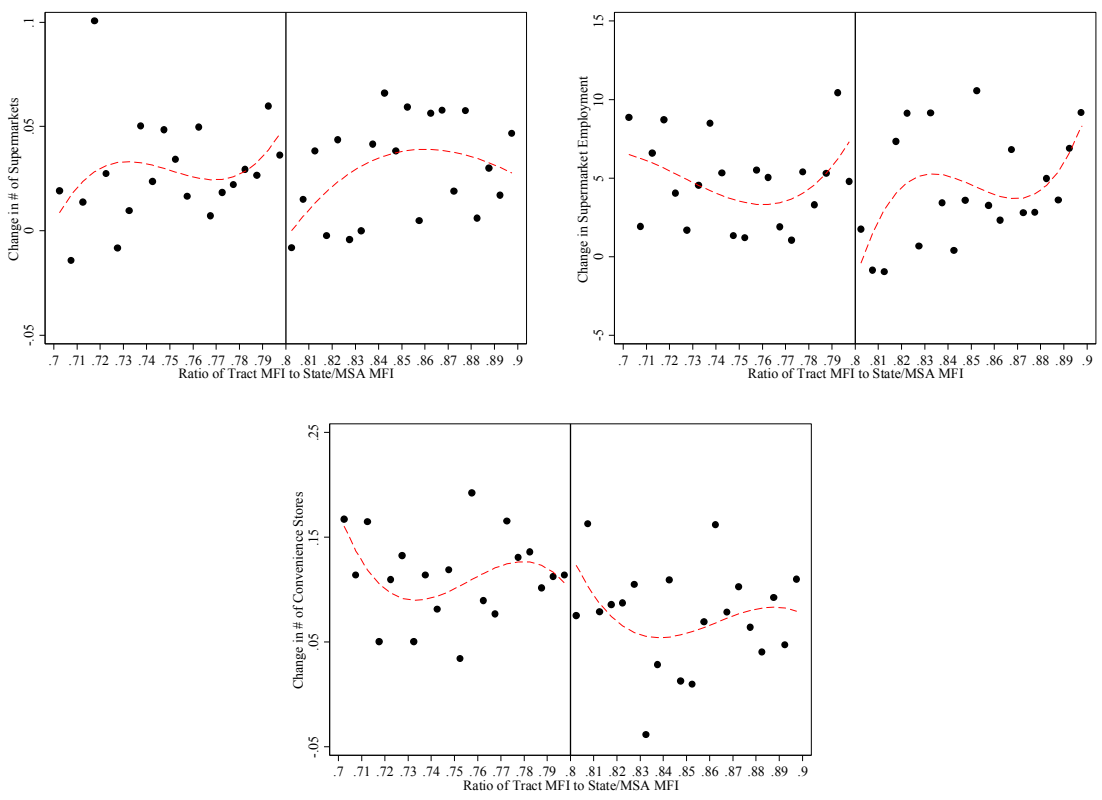

Figure 4. Supermarket and convenience store growth at the LIC MFI ratio eligibility threshold. Source: Decennial Census and TDLinx. 